\title{
Москвина М.В.
}

\section{Психолого-педагогические аспекты толерантности педагогов в условиях инклюзивного образования}

\author{
Moskvina M.V. \\ Psychological and pedagogical aspects of tolerance of \\ teachers in the context of inclusive education
}

В статье рассматриваются современные условия воспитания, обучения, развития и

функционирования общества в инклюзивном образовании, которые требуют особое терпимое отношение к проблеме социализации личности, а так же характеристике уровней сформированности инклюзивной готовности педагогов с позиции социально-личностных компетенций

Ключевые слова: социально-личностные компетенции, терпимое отношение, инклюзивное образование, современные условия, личностные особенности педагога, образовательная среда, ценности, личностная культура

\section{Москвина Маргарита Витальевна}

Доцент

Норильский филиал Красноярского краевого института повышения квалификации работников образования

2. Норильск, ул. Ленинградская, 7 A
The article considers modern conditions of education, training, development and functioning of society in inclusive education which demand special tolerance to the problem of socialization and the characteristics of levels of development inclusive of the readiness of teachers from the viewpoint of social and personal competences

Key words: social and personal competence, tolerance, inclusive education, modern facilities, personal characteristics of the teacher, the learning environment, values, personality culture

Особенность нынешнего этапа в развитии нашей стра ны: парадоксальность взаимоотношений, разделение об щества, игнорирование проблем социального развития молодёжи, все это настоятельно требуют осмысления функций социальных институтов в отношении к детям и создания условий для их жизнедеятельности [1].

Эффективность реализации образовательной инклюзии во многом зависит от готовности педагога, к работе со всеми субъектами инклюзивного образовательного пространства: типичными и «особыми» детьми, их родителями, специалистами (учителями-дефектологами, логопедами, психологами, социальными педагогами и др.). Эта готовность детерминируется спецификой условий профессиональной деятельности педагога (полисубъектность инклюзивного 
образовательного пространства - дети с ОВЗ, дети с типичным развитием, родители обеих групп детей, специалисты) и предполагает сформированность ряда академических, социально-личностных (базовых) и профессиональных компетенций.

Одной из причин, препятствующих реализации задач инклюзии детей с ООП, является недостаточно сформированные социально-личностные компетенции педагогов:

- социальное взаимодействие и общение (социальная и профессиональная (инклюзивная) толерантность по отношению ко всем субъектам инклюзивного образования; владение навыками межличностного взаимодействия и коммуникации; обладание стратегиями поведения в конфликтной ситуации (умение работать в команде);

- социально-правовые компетенции (способность брать на себя ответственность; умение адвокатировать права субъектов образовательной инклюзии);

- поведенческие компетенции (критическое мышление; владение навыками здоровьесбережения и самосохранительного поведения; наличие самомотивации - умение сохранять надежду и настаивать на своем, несмотря на неудачи; контролирование собственного настроения и др.) [2].

Важным условием, обеспечивающим своеобразие взаимодействия в педагогическом процессе, является характер отношений, который складывается между всеми его участниками: педагогами, детьми, администрацией, родителями. Эти отношения многообразны, каждое из них имеет мотивационно-ценностный, когнитивный и эмоциональный компоненты. Среди всего многообразия отношений особое место занимает терпимое отношение. Не случайно терпение, терпимость в народной педагогике возводятся в ранг одних из ведущих качеств личности.

Терпимость присуща педагогу, который спокойно реагирует на внешний вид, индивидуальные особенности и поведение детей (у других людей это может вызывать раздражение), способен не только принять их качества, в том числе негативные, поведение такими, какие они есть, но и понять, что стоит изменять, а что не стоит.

Ведущая роль в педагогическом процессе, принадлежит учителю, педагогу, а влияние учителя на своих учащихся, воспитанников и других субъектов образовательной деятельности реализуется в процессе педагогического общения и деятельности. Характер этого влияния во многом зависит от свойств и качеств личности педагога, его профессиональной компетентности, уровня любви и авторитета. Исходя из вышесказанного, в нашем исследовании мы, прежде всего, обратились к индивидуально - психологическим особенностям личности педагога, которые могут лежать в реализации принципа толерантности в контексте инклюзивного образовательного взаимодействия.

В практике преподавания слушателям курсов повышения квалификации по образовательной программе «Технологии здоровьесберегающей среды в образовательном учреждении» (2008-2011 гг.), нами было предложено респондентам (СП), (СОШ), (ДОУ), выразить свое отношение к различным субъектам 
педагогической реальности: себе, администрации, коллегам, детям, родителям, общественности, СМИ и указать уровень терпимого, толерантного, нетерпимого отношения к ним по пятибалльной шкале.

Основу исследования составил опросник «Опросник на выявление терпимого, толерантного, нетерпимого отношения к субъектам педагогической реальности». Цель данного исследования: изучение отношений педагога к различным субъектам педагогической реальности и выявляется индивидуальная картина предпочтений (избегания) тех или иных объектов педагогической реальности и уровень терпимого, толерантного, нетерпимого отношения к ним в условиях инклюзивного образования.

Исходя из результатов исследования, экспериментальной группы (СП) и контрольных групп (СОШ, ДОУ) педагоги, оценившие нетерпимое отношение к себе - 28\%. Самый высокий показатель - 50\% - это негативное отношение к администрации. Чуть меньше к общественности и СМИ выразили - 45\%. К коллегам выразили -23,3\%. Негативное отношение к детям составило - 27\%, к родителям - 32\%. Толерантное отношение педагогов к себе составило - 35,3\%, к администрации -35\%, к коллегам составило самый высокий показатель - 47,3\%, в равной степени составили родители -38\%,общественность с СМИ - 39\% с разницей в 1\%. Наименьший показатель по отношению к детям -30\%. Терпимое отношение к себе - 36,7\%, к администрации - 15\%, общественности и СМИ $16 \%$. Таким образом, полученные результаты позволяют выдвинуть предположение о том, что терпимое отношение педагогов к различным субъектам педагогической реальности и в том числе к детям, учащимся с ООП в условиях инклюзивного образования не стабильное. Необходимо существуют определенные проблемы в личностно-профессиональном развитии педагогов, что негативно влияет на психологическое здоровье всех субъектов педагогической реальности. Важным фактором достижения терпимого отношения педагога к детям и учащимся с ОВЗ и к другим субъектам профессиональной деятельности, должен стать процесс саморазвития, что возможно в системе курсов повышения квалификации.

\section{Список используемых источников:}

1. Кочисов В.К., Гогицаева О.У. Психолого-педагогические аспекты социализации личности ребенка // Вектор науки ТГУ. Серия: Педагогика, психология. 2013. № 4

2. Хитрюк В.В. Готовность педагога к работе с «особым» ребенком: модель формирования ценностей инклюзивного образования // Вестник Балтийского федерального университета им. И. Канта. 2013. Bыn. 11. C. 72-79.

(C) 2015, Москвина М.В.

Психолого-педагогические аспекты толерантности педагогов в условиях инклюзивного образования
(C) 2015, Moskvina M.V.

Psychological and pedagogical aspects of tolerance of teachers in the context of inclusive education 